\title{
Mandible Fractures
}

\author{
Brent B. Pickrell, MD ${ }^{1}$ Arman T. Serebrakian, MD, MS ${ }^{1}$ Renata S. Maricevich, MD²
}

${ }^{1}$ Division of Plastic Surgery, Harvard Medical School, Boston, Massachusetts

2 Division of Plastic Surgery, Michael E. DeBakey Department of Surgery, Baylor College of Medicine, Houston, Texas

Semin Plast Surg 2017;31:100-107.
Address for correspondence Renata S. Maricevich, MD, 6701 Fannin Street, CC 610.00, Houston, TX 77030

(e-mail: Renata.Maricevich@bcm.edu).

\author{
Abstract \\ Keywords \\ - mandibular fracture \\ - occlusion \\ - facial trauma \\ - open reduction \\ - maxillomandibular \\ fixation
}

Mandible fractures account for a significant portion of maxillofacial injuries and the evaluation, diagnosis, and management of these fractures remain challenging despite improved imaging technology and fixation techniques. Understanding appropriate surgical management can prevent complications such as malocclusion, pain, and revision procedures. Depending on the type and location of the fractures, various open and closed surgical reduction techniques can be utilized. In this article, the authors review the diagnostic evaluation, treatment options, and common complications of mandible fractures. Special considerations are described for pediatric and atrophic mandibles.
Mandible fractures are regularly encountered by plastic surgeons and account for a significant portion of maxillofacial injuries. The majority of adult mandible fractures in the United States are related to interpersonal violence, most frequently in men aged 18 to 24 years old. ${ }^{1}$ A review $^{1}$ of 13,142 patients noted that men have a fourfold higher incidence of mandibular fractures with nearly $50 \%$ arising from assault. In contrast, women sustain mandible fractures more commonly from motor vehicle accidents (MVAs) and falls. ${ }^{1-3}$ It is reported that $\sim 25 \%$ of mandible fractures in women are secondary to falls, ${ }^{1}$ although domestic violence should be ruled out if the mechanism and fracture location are inconsistent with accidental trauma.

In recent years the injury pattern and epidemiology of facial fractures has changed with improved safety technology in passenger vehicles. ${ }^{4}$ Recent reports ${ }^{5,6}$ suggest that the combination of a seatbelt and airbags decreases the likelihood of sustaining a facial fracture during a MVA by over $50 \%$.

\section{Evaluation}

\section{Initial Assessment}

Patients should be assessed in accordance with the Advanced Trauma Life Support protocol. Life-threatening injuries should be recognized and treated accordingly. Verifying the mechanism of injury can prove valuable as the type of trauma is often related to fracture patterns. Physical altercations tend to result in a higher incidence of angle fractures due to a lateral blow to the mandible, whereas MVAs are more commonly associated with parasymphyseal, symphyseal, body, and condylar fractures. ${ }^{1,7,8}$ Concomitant injuries must be ruled out during primary and secondary trauma surveys, especially after MVAs; a careful evaluation of the Cspine is required before proceeding with any operative management. Most studies report an incidence of C-spine injuries between 2 to $10 \%^{9-14}$ in patients presenting with facial fractures, although this may be as high as $20 \%$ in patients with panfacial injuries. ${ }^{15}$ Combined facial fracture patterns, involving two or more facial thirds, and unilateral mandible injuries account for the greatest number of $\mathrm{C}$-spine injuries. $^{16,17}$

\section{Examination}

A critical factor in the diagnostic workup of mandible fractures is the evaluation of the patient's occlusion. Asking patients if their "bite feels normal" is a very effective and highly sensitive test in the acute setting. A subjective report of malocclusion by the patient should be taken seriously, documented, and compared with the preinjury occlusion. If the patient is intubated, sedated, or unable to communicate this information, prior dental records can be helpful in addition to an examination of the wear facets. Most patient's
Issue Theme Facial Trauma; Guest Editors: Renata S. Maricevich, MD, and Tuan A. Truong, MD
Copyright (c) 2017 by Thieme Medical Publishers, Inc., 333 Seventh Avenue, New York, NY 10001, USA Tel: +1(212) 584-4662.
DOI http://dx.doi.org/ 10.1055/s-0037-1601374. ISSN 1535-2188. 
preinjury occlusion is imperfect, and the surgeon should not attempt to place the patient into a "normal occlusion" if the wear facets indicate a different preinjury skeletal relationship.

On exam, the physician should bimanually palpate the fracture site to check for fragment mobility. A lack of mobility indicates a stable fracture that may be amenable to conservative management, provided the occlusion has not been altered. Intraoral lacerations, injuries of the soft tissues, and hematomas at the fracture site are also important to note as these may lead to an increased risk of infection. Ecchymosis of the floor of the mouth is classically pathognomonic for mandibular fractures.

The dental status of the patient should also be evaluated. Loose teeth are extremely common following facial trauma and should be noted during the initial assessment. Exceedingly carious or damaged teeth, particularly at the fracture site, should prompt consideration of extraction. Tooth extraction is recommended if the tooth is (1) luxated from its socket and/or interfering with fracture reduction, (2) fractured, (3) has advanced dental caries carrying a significant risk of abscess, (4) has advanced periodontal disease with mobility that would not contribute to establishing stable occlusion, or (5) has existing pathology such as cyst formation and pericoronitis. ${ }^{18}$ There are certain situations in which teeth in the fracture line can be left in place as they can provide a larger repositioning surface. They can also be used for the application of tension bands in certain cases ${ }^{19}$ and do not cause delayed healing when treated with a closed reduction. ${ }^{20}$

Sensation in the lower lip should also be tested and recorded. Damage to the inferior alveolar nerve (IAN) as it courses through the body of the mandible is not uncommon with mandible fractures, and failure to note this preoperatively may be mistaken as a postoperative complication. We have noted mandibular angle fractures to have significantly higher rates of hypoesthesia. Tay et al $^{21}$ found that IAN injury was 4 times more likely in IAN-bearing posterior mandibular fractures (56.2\%) than in non-IAN-bearing anterior mandibular fractures (12.6\%).

\section{Imaging}

Radiographic assessment is integral in the workup of patients with significant facial trauma. Most patients with mandible fractures, particularly in the setting of polytrauma, present to an emergency room and undergo initial computed tomographic (CT) imaging to evaluate for cervical spine (C-spine) and other concomitant injuries. Although panoramic tomography used to be the gold standard, is cost-effective, and useful in the assessment of dental trauma, ${ }^{22}$ certain fracture patterns may be missed, particularly in the posterior mandible. Therefore, with helical CT imaging $100 \%$ sensitivity in diagnosing mandible fractures compared with $86 \%$ sensitivity of panoramic tomography imaging, ${ }^{22}$ together with the advent of three-dimensional reconstruction, CT is the current diagnostic tool of choice for the radiographic evaluation and diagnosis of mandible fractures. $^{23}$

\section{Management}

The ultimate goal of treatment is to re-establish the patient's preinjury dental occlusion. Fractures that are nondisplaced and exhibit no occlusal changes may be amenable to nonsurgical management, but the majority of mandible fractures will require stabilization for satisfactory healing and to restore pretraumatic maxillomandibular orientation. Various treatment strategies have been described and vary widely depending on the fracture location and surgeon's preference. The patient's demographics, comorbidities, dentition, and fracture characterization will all influence the choice of fixation by the treating surgeon.

\section{Fracture Fixation Principles}

Fracture fixation can be divided into two basic categories: load-bearing and load-sharing. Load-bearing osteosynthesis denotes a construct that is capable of bearing $100 \%$ of the functional load generated by the mandible such that the bone at the fracture site bears none, ${ }^{18,24}$ effectively sheltering the bone from masticatory forces as it heals. This is frequently accomplished with locking reconstruction plates. Clinical uses of load-bearing fixation include defect fractures, comminuted fractures, and fractures in severely atrophic mandibles. By comparison, load-sharing osteosynthesis denotes a fixation arrangement whereby the functional load is distributed between the hardware and the bony ends at the fracture site. ${ }^{18,24}$ Understandably, this requires sufficient bony buttressing at the fracture site and cannot be used for fractures with poor bone-to-bone contact, comminuted, or defect fractures. Examples of load-sharing fixation include a single miniplate along the oblique ridge for angle fractures, a single miniplate and an arch bar for body or symphyseal fractures, and lag screw fixation.

Maxillomandibular fixation can be performed with the use of Erich arch bars, hybrid arch bars, intermaxillary fixation screws, circummandibular and piriform wiring, and orthodontic brackets with hooks.

\section{Surgical Treatment by Fracture Site}

\section{Body}

Nondisplaced and minimally displaced fractures of the mandibular body can often be managed closed with a period of maxillomandibular fixation (MMF), particularly when the fracture is isolated and reducible and the dentition is sufficient. However, this practice results in prolonged immobility and challenges with intraoral hygiene. As such, open reduction, internal fixation (ORIF) may be preferable for some patients, particularly the elderly, to avoid the discomfort and hindrance of dental wiring. Indeed, more displaced fractures of the mandibular body will generally require ORIF for optimal anatomical reduction. Exposure is obtained via a lateral gingivobuccal sulcus incision, although an extraoral submandibular (Risdon) approach can be utilized if necessary. ${ }^{25}$ Fixation is commonly achieved by using a single large plate along the inferior border or by two smaller plates, one on the inferior border and another placed just above, sparing the tooth roots, 
the latter functioning as a tension band. Ellis reviewed ${ }^{26} 682$ patients treated with ORIF of body and/or symphyseal fractures and found that the use of two miniplates was associated with more postoperative complications than the use of one stronger plate, such as noninfectious wound dehiscence and the need for hardware removal due to exposure.

\section{Symphysis/Parasymphysis}

Fractures of the anterior mandible are often secondary to a posteriorly directed force, frequently in the context of MVAs. Given the strength of bone in this region of the mandible, one should always look for concomitant mandibular fractures as well as C-spine injuries from neck hyperextension.

Open reduction, internal fixation is generally the treatment of choice for symphyseal and parasymphyseal fractures, although closed treatment is still an accepted alternative for select patients with simple nondisplaced fractures. Exposure of the fracture is obtained with a lower gingivobuccal sulcus incision and dissection to the inferior border of the mandible. Two miniplates are sufficient in most situations and result in similar outcomes, but with more postoperative complications, as mentioned above. ${ }^{26,27}$ One larger plate, with or without an arch bar, is the accepted alternative to the two miniplate approach. In the parasymphyseal region, the surgeon should employ careful dissection around the mental nerve to allow placement of the inferior plate below the mental foramen. Two lag screws that span the fracture line provide rigid fixation with relatively low treatment costs. However, these long screws are difficult to apply correctly and can result in shearing of the fracture fragments and subsequent malocclusion if good bone-tobone contact is not present. As such, some feel that this procedure is very technique sensitive and thus requires more skill and expertise (- Fig. 1). ${ }^{27}$
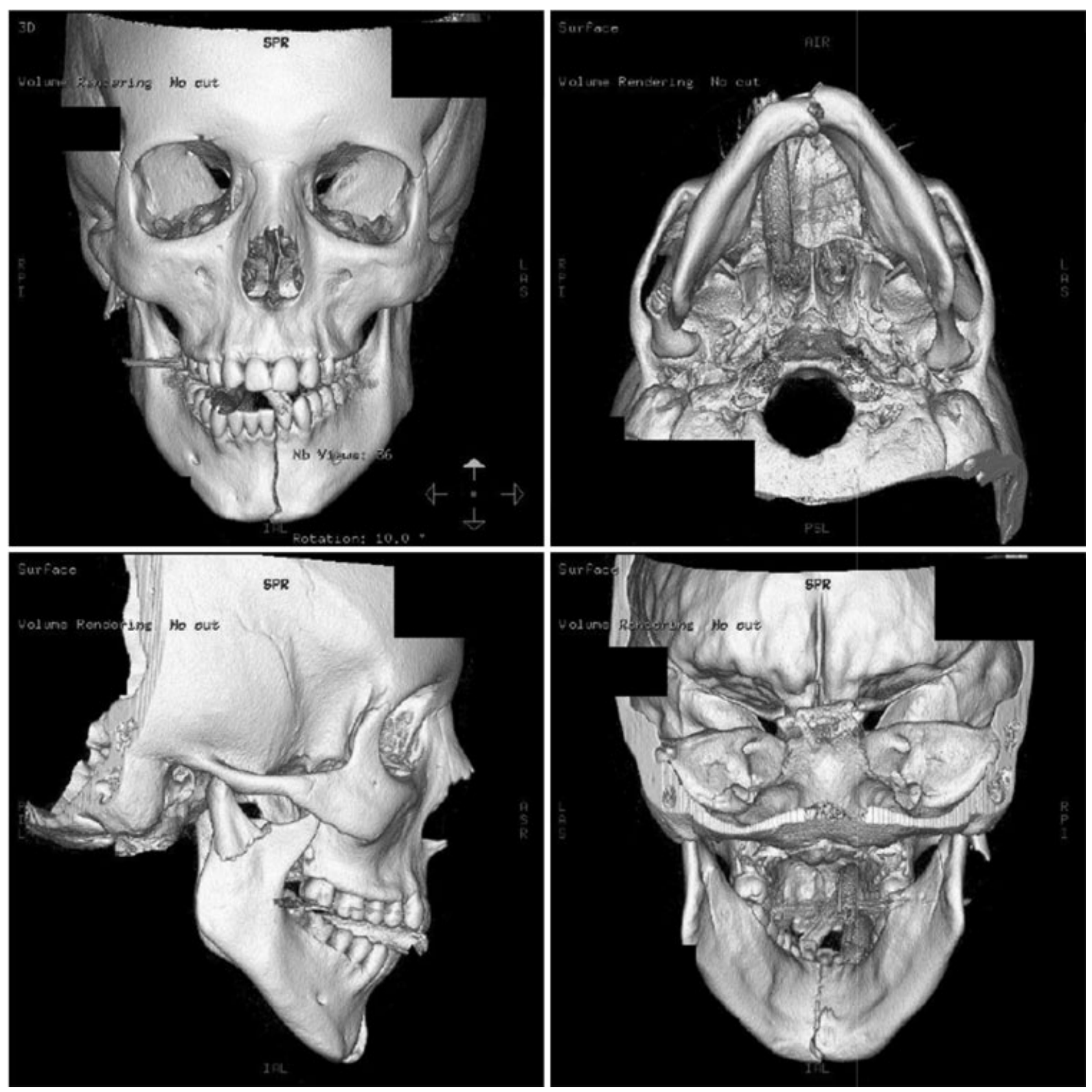

Fig. 1 Displaced symphyseal and right subcondylar fractures. 


\section{Angle}

The angle is the most frequently involved site in patients with isolated mandibular fractures, which typically result from personal assault. ${ }^{28}$ The thinner cross-sectional area of this region of the mandible ${ }^{29}$ and the presence of impacted third molars ${ }^{30}$ are thought to primarily contribute to the high incidence of angle fractures. Mandibular angle fractures are some of the most technically demanding and are associated with the highest complication rate of all mandibular fractures. ${ }^{31-33}$

Disagreement exists in the literature regarding the precise definition of a mandibular "angle" fracture, ${ }^{34}$ contributing to the various management approaches. The anatomical region contains several powerful muscles capable of generating significant forces in multiple directions that must be accounted for. ${ }^{35}$ Champy showed that by accounting for the forces of these muscles absolute rigid fixation is not necessary. ${ }^{36}$ Nondisplaced or minimally displaced fractures in patients with normal occlusion may be treated with observation and a soft diet or a short course of MMF with close follow-up. However, most angle fractures are treated with some form of ORIF due to the tendency of proximal segment displacement. Common strategies to stabilize these fractures have included a single plate along the oblique ridge, two lateral border plates, or a matrix-type miniplate on the lateral border (-Fig. 2). An intraoral approach using a vestibular incision is used for the majority of simple angle fractures. In comminuted or more complex fractures, a transbuccal trocar can be employed to improve access.

A landmark study in 2010 by Ellis looked at a series of 185 patients with angle fractures over a 12 -year period treated in one of three ways: (1) 5 to 6 weeks of MMF, (2) ORIF using a single miniplate, and (3) ORIF using two miniplates. Only the third technique produced rigid fixation, but the single miniplate approach along the external oblique ridge was associated with the lowest number of complications, the shortest operating room time, and was the easiest to perform. ${ }^{32}$
The risk of postoperative complications was reduced when the single miniplate was placed on the lateral surface of the mandible (transbuccal) compared with placement on the external oblique ridge. The use of geometric miniplates was also found to decrease the risk of postoperative complications compared with the use of conventional miniplates. ${ }^{37}$ In the rare setting of bilateral mandibular angle fractures, the combination of transoral rigid and nonrigid fixation with 2.0-mm miniplates has been described. ${ }^{38}$

\section{Condyle}

Mandibular condyle fractures account for 25 to $35 \%$ of all mandibular fractures. ${ }^{3,39-41}$ These patients will typically present with preauricular pain, malocclusion, or a chin deviation with mandibular opening and closing. In patients with bilateral condylar fractures, premature contact of the posterior teeth leads to the classic anterior open-bite deformity. History of a traumatic force directed at the symphyseal region may also be present, and these fractures are frequently found in association with fractures of the symphysis/ parasymphysis.

The management of mandibular condyle fractures is very controversial among maxillofacial surgeons. ${ }^{42}$ The lack of robust data and standardized definitions regarding fracture classification contribute to the ongoing debate about proper treatment. However, there is general agreement that patients with condylar fractures benefit from early active range-of-motion (ROM) to rehabilitate the temporomandibular articulation.

It is important to distinguish between fractures of the condyle itself (intracapsular) and fractures of the condylar neck (extracapsular). Fractures of the head of the condyle are generally treated closed because the fracture fragments are typically insufficient for fixation and the location within the temporomandibular joint (TMJ) places the patient at risk for ankylosis. Patients with no malocclusion can usually forgo MMF and be placed on a soft diet with close follow-up. If

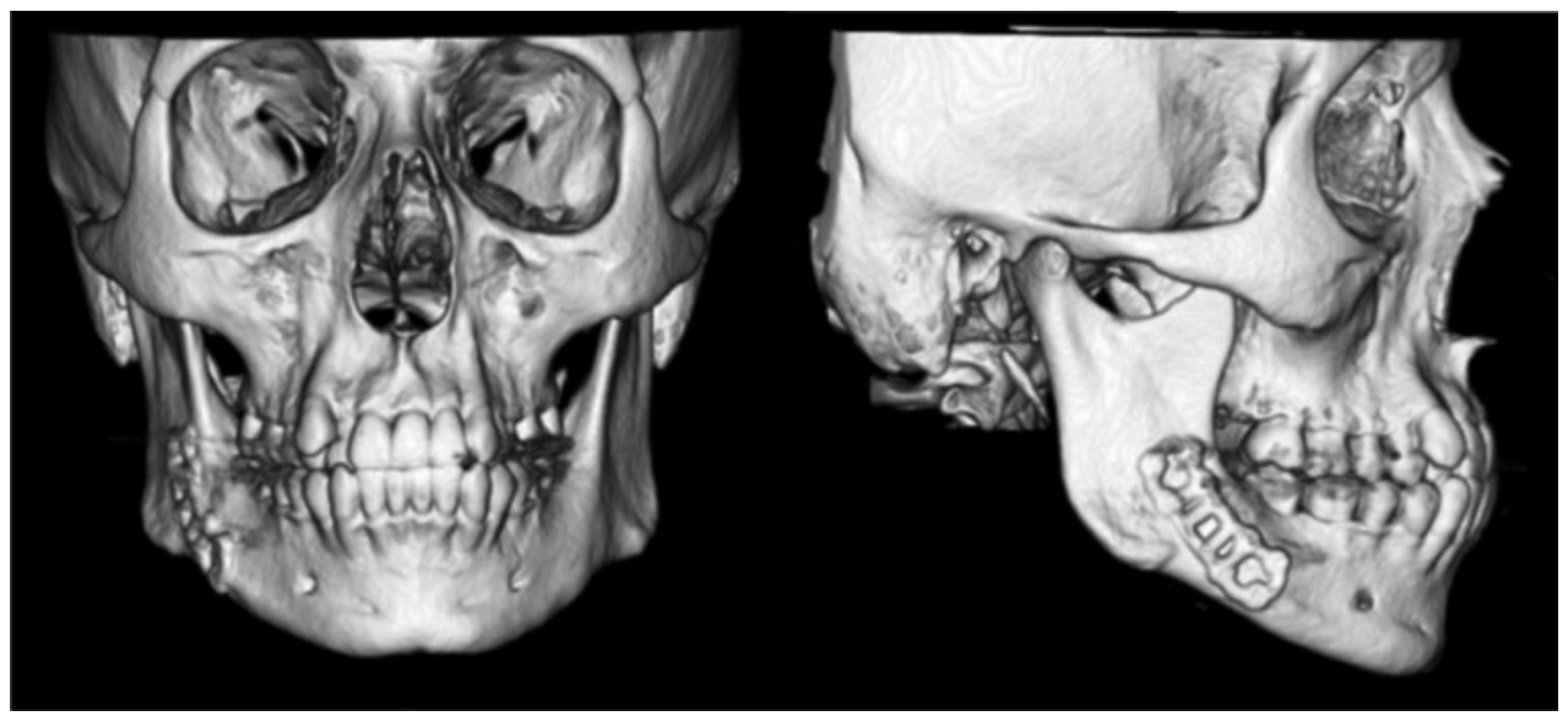

Fig. 2 Postoperative angle fracture repaired with a ladder miniplate. 
malocclusion is present, MMF is necessary, and occlusion is controlled with elastics.

Fractures of the condylar neck and subcondylar region can result in more serious occlusal disturbances. Management options include closed or open treatment, by either a direct approach or endoscopically. Previous studies have supported a more conservative approach because conservative treatment produced similar occlusal and functional outcomes to those treated with ORIF, ${ }^{43,44}$ and there is an alleged risk of devascularization of the fractured segment in addition to the visibility of external scars with the open approach. ${ }^{45-47}$ Facial nerve injury is also a purported risk of ORIF, but cases seem to be largely temporary with total recovery in less than 6 months. ${ }^{45}$

Advocates for ORIF report improved pain control, occlusion, and the restoration of posterior ramus height with the open approach. ${ }^{48-50}$ Additionally, long-term complications such as pain, arthritis, malocclusion, TMJ dysfunction, facial asymmetry, and ankylosis are reported in patients with condylar injuries treated in a closed fashion. ${ }^{51-53} \mathrm{~A}$ metaanalysis by Al-Moraissi and Ellis ${ }^{51}$ in 2015 found that ORIF provided superior functional clinical outcomes, such as MIO, protrusion, and a lack of chin deviation, compared with a closed treatment. The authors also found improvements in postoperative pain reduction and occlusion in those treated in an open manner. ${ }^{51}$ Although objective outcome measures do appear to vary with treatment selection, some authorities ${ }^{42}$ feel that the management of these fractures should ultimately depend on the skill and comfort level of the surgeon, and whether they feel they can achieve the goals of treatment better with open versus closed treatment.

Bilateral subcondylar fractures represent a unique challenge and have higher rates of complications, ${ }^{40,54}$ including malocclusion rates of up to $5 \%{ }^{55}$ Rehabilitating these patients using conservative treatment is more difficult due to the deficiency in structural support from the lack of craniomandibular articulations. ${ }^{51}$ Although there are reports of these fractures being managed conservatively with low malocclusion and pain rates, ${ }^{56}$ treating at least one of the fractures with ORIF to re-establish posterior facial height may be the best form of treatment. ${ }^{57}$ Other indications for ORIF are open fractures, the presence of a foreign body at the fracture site, and the displacement of a fractured fragment into the middle cranial fossa.

\section{Special Considerations}

\section{Atrophic Mandible Fractures}

The atrophic mandible is more vulnerable to fracture because of decreased bone volume as a result of the resorption of alveolar bone due to tooth loss. ${ }^{58}$ Fractures occur most commonly in the mandibular body where atrophy appears critical. Atrophic fractures most often occur in the geriatric population, but are infrequent injuries in clinical practice. These patients are also at particularly high risk for nonhealing secondary to the tenuous blood supply and poor bone stock of the atrophic mandible. ${ }^{59}$ Complication rates, including nonunion, have been reported between 4 to $20 \% .{ }^{60-66}$

The lack of teeth in these patients and the associated small-cross sectional area of the jaw preclude some traditional methods of fracture immobilization, especially MMF. $^{58}$ Because many of these patients are medically debilitated, considering no treatment for these fractures is acceptable. ${ }^{67,68}$ For patients undergoing intervention, closed and open treatments have been described. Bruce and Ellis ${ }^{61}$ published a series of 104 consecutive edentulous fractures and found higher rates of delayed or fibrous union in closed treatment versus ORIF ( $25 \%$ vs. $12.6 \%$ ). There was also increased morbidity and disability time, worse jaw function, and poorer aesthetics in those who underwent closed treatment. ${ }^{61}$ In patients who are medically stable to undergo general anesthesia, ORIF with immediate bone grafting can yield good outcomes. ${ }^{58}$ Given the poor blood supply of the atrophic mandible, bone grafting allows for facilitating osseous union, providing stability to the fracture, and adding bulk to prevent pathologic fracture and enhance the possibilities for prosthetic reconstruction through augmenting the alveolus. ${ }^{58}$

\section{Pediatric Fractures}

Mandible fractures represent up to $40 \%$ of pediatric facial fractures, most frequently as a result of MVAs and falls. Sports-related injuries and assault are common causes in teenagers. ${ }^{69-72}$ Mandible fractures also differ between sexes, with a male to female ratio of $4: 1 .^{73}$

In comparison to adult fractures, pediatric fractures are approached differently due to the stage of mixed dentition, the elasticity of the craniofacial skeleton, and the potential for remodeling of the bone and fracture site with growth. ${ }^{74,75}$ The high elasticity of the cortical bone accounts for why most pediatric mandible fractures are unicortical and minimally displaced. $^{76}$

A key aspect that distinguishes the pediatric mandible fracture is the dentition, requiring the surgeon to consider the developmental status of the child in the context of their injury. Until the mixed dentition phase is complete, the parasymphysis and body of the mandible are occupied by developing tooth buds. The location of unerupted permanent tooth follicles is an important consideration in terms of where plate-and-screw fixation can be placed during the operative repair of pediatric mandible fractures. ${ }^{77}$

The most common mandible fractures in children involve the condyle $(40-70 \%),{ }^{77,78}$ which is considered a primary growth center of the jaw. Direct trauma to the anterior mandible can result in proximal transmission of force, leading to injury of the mandibular condyle. Forces transmitted to this region often result in intra-articular fractures. Such fractures are associated with a risk for growth disturbance of the mandible, resulting in facial asymmetry due to ipsilateral chin deviation. ${ }^{79-81}$ The risk of growth disruption appears to be highest in cases of comminuted intra-articular fractures. $^{82}$ The clinical presentation of these children can be very misleading, as they may present to the emergency room with simply a chin laceration and jaw pain. 


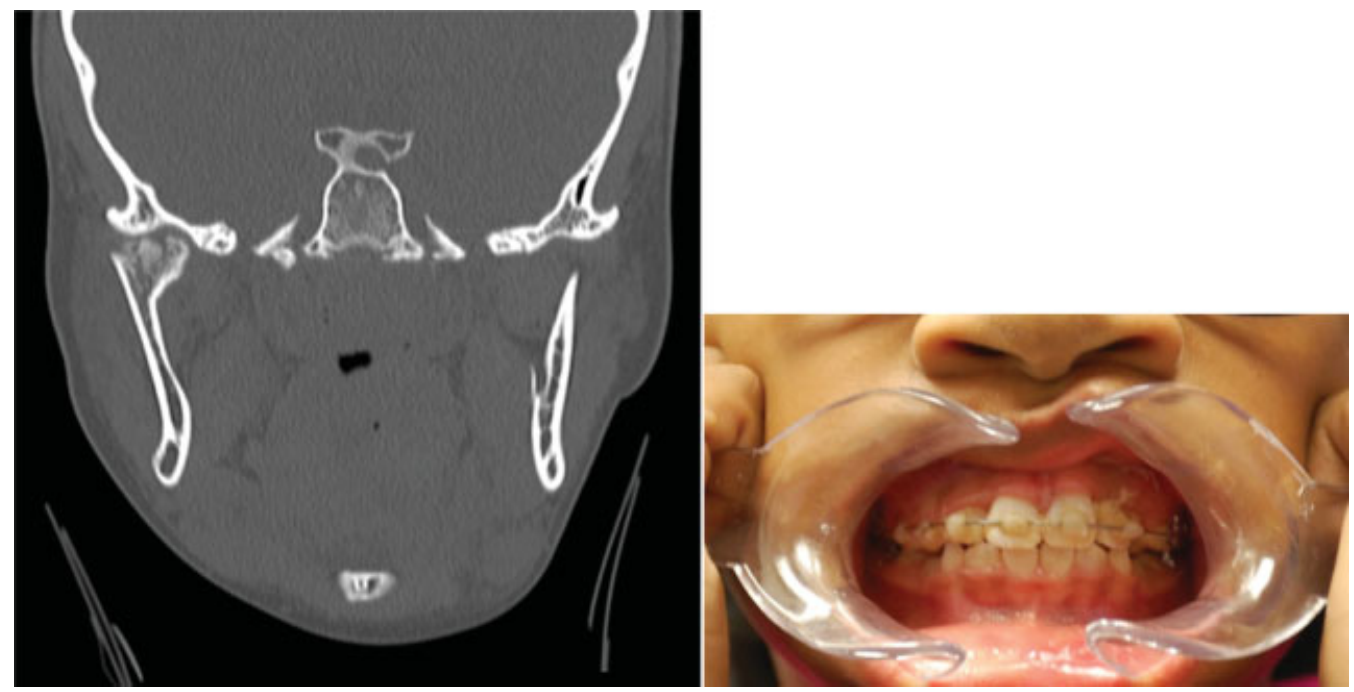

Fig. 3 Child with condylar fracture successfully treated with short-course maxillomandibular fixation and contralateral elastics.

Similar to the adult literature, the management of pediatric condylar fractures is a contentious topic. Three main treatment modalities have been described, including mandibular physical therapy consisting of ranging exercises without MMF, a short period of MMF followed by mandibular physical therapy, and ORIF. In general, these injuries rarely require operative management as children usually have good ROM and occlusion. Long-term favorable facial growth outcomes have been described with the closed treatment of condylar fractures. ${ }^{83,84}$

When an intra-articular condylar fracture is diagnosed, attention must be focused on early mobilization and ROM exercises. The condyle is a very vascular structure in children and can fragment under traumatic compression, leading to hemarthrosis and ankylosis. Temporomandibular joint ankylosis is very difficult to treat successfully, and in a child can result in profound deformities, as the injured side fails to grow appropriately (-Fig. $\mathbf{3}$ ).

In condylar neck or subcondylar injuries, there is a greater chance for more significant occlusal changes. Very young children have exceptional fracture remodeling ability, and the developing dentition can frequently self-correct some degree of malocclusion. A short period of MMF (7-14 days) can be considered for older children or for those patients with more significant malocclusions. Standard Erich arch bars can be a challenge in the mixed dentition stage, but can still be used with no reported periodontal defects, tooth avulsions, or disturbances to permanent dentition. ${ }^{85}$

In fractures of the angle, body, or symphysis/parasymphysis, ORIF is frequently required. In general, $2.0-\mathrm{mm}$ miniplates with monocortical screws or wires along the inferior border are the preferred methods of fixation. ${ }^{77}$ A preoperative panoramic radiograph is useful in evaluating the position of the developing tooth buds. The surgeon should exercise caution when plating the inferior-most aspect of the anterior mandibular border to avoid injury to unerupted tooth follicles and the low-lying AIN in the pediatric pa- tient. ${ }^{77}$ Radiographs should also be taken postoperatively to ensure that none of the screws are transfixing a tooth bud. If this is seen, the plate should be removed once the fracture has sufficiently healed.

\section{Complications}

Mandible fracture complication rates range from 7 to $29 \%$ and have been correlated to fracture severity, injury site, and the number of involved sites. ${ }^{28}$ The most common complications include infection, hardware failure, osteomyelitis, nonunion, malunion, and wound dehiscence. ${ }^{86-88}$ Higher complication rates are seen among smokers, patients with systemic illnesses, and those patients with substance use or abuse. Antibiotic usage and delay in surgical repair do not seem to affect the incidence of these complications. Complications are less prevalent in children, which are mostly related to infection. ${ }^{89}$

In multiple studies, nonunion was most common in the mandibular body and was associated with inadequate stabilization or reduction and multiple fractures, and the presence of medical or social risk factors. ${ }^{90,91}$

Malocclusion remains the most functionally significant postoperative complication and is most often due to technical error in the placement of the fixation. This should be recognized at the end of the case when MMF is released, and the final occlusion is assessed. If noted postoperatively, most patients should be returned to the operating room as this complication cannot be reliably treated with nonsurgical modalities.

\section{References}

1 Afrooz PN, Bykowski MR, James IB, Daniali LN, Clavijo-Alvarez JA. The epidemiology of mandibular fractures in the United States, part 1: a review of 13,142 cases from the US National Trauma Data Bank. J Oral Maxillofac Surg 2015;73(12):2361-2366 
2 Erdmann D, Follmar KE, Debruijn M, et al. A retrospective analysis of facial fracture etiologies. Ann Plast Surg 2008;60(4):398-403

3 Ellis E III, Moos KF, el-Attar A. Ten years of mandibular fractures: an analysis of 2,137 cases. Oral Surg Oral Med Oral Pathol 1985; 59(2):120-129

4 Murphy RX Jr, Birmingham KL, Okunski WJ, Wasser T. The influence of airbag and restraining devices on the patterns of facial trauma in motor vehicle collisions. Plast Reconstr Surg 2000;105(2):516-520

5 Hitosugi M, Mizuno K, Nagai T, Tokudome S. Analysis of maxillofacial injuries of vehicle passengers involved in frontal collisions. J Oral Maxillofac Surg 2011;69(4):1146-1151

6 Hyman DA, Saha S, Nayar HS, Doyle JF, Agarwal SK, Chaiet SR. Patterns of facial fractures and protective device use in motor vehicle collisions from 2007 to 2012. JAMA Facial Plast Surg 2016; 18(6):455-461

7 Lamphier J, Ziccardi V, Ruvo A, Janel M. Complications of mandibular fractures in an urban teaching center. J Oral Maxillofac Surg 2003;61(7):745-749, discussion 749-750

8 Olson RA, Fonseca RJ, Zeitler DL, Osbon DB. Fractures of the mandible: a review of 580 cases. J Oral Maxillofac Surg 1982; 40(1):23-28

9 Beirne JC, Butler PE, Brady FA. Cervical spine injuries in patients with facial fractures: a 1-year prospective study. Int J Oral Maxillofac Surg 1995;24(1 Pt 1):26-29

10 Sinclair D, Schwartz M, Gruss J, McLellan B. A retrospective review of the relationship between facial fractures, head injuries, and cervical spine injuries. J Emerg Med 1988;6(2):109-112

11 Haug RH, Wible RT, Likavec MJ, Conforti PJ. Cervical spine fractures and maxillofacial trauma. J Oral Maxillofac Surg 1991; 49(7):725-729

12 Luce EA, Tubb TD, Moore AM. Review of 1,000 major facial fractures and associated injuries. Plast Reconstr Surg 1979;63(1):26-30

13 Baker $A B$, Mackenzie W. Facial and cervical injuries. Med J Aust 1976;1(8):236-237

14 Mulligan RP, Friedman JA, Mahabir RC. A nationwide review of the associations among cervical spine injuries, head injuries, and facial fractures. J Trauma 2010;68(3):587-592

15 Stacey DH, Doyle JF, Gutowski KA. Safety device use affects the incidence patterns of facial trauma in motor vehicle collisions: an analysis of the National Trauma Database from 2000 to 2004. Plast Reconstr Surg 2008;121(6):2057-2064

16 Elahi MM, Brar MS, Ahmed N, Howley DB, Nishtar S, Mahoney JL. Cervical spine injury in association with craniomaxillofacial fractures. Plast Reconstr Surg 2008;121(1):201-208

17 Mithani SK, St-Hilaire H, Brooke BS, Smith IM, Bluebond-Langner $\mathrm{R}$, Rodriguez ED. Predictable patterns of intracranial and cervical spine injury in craniomaxillofacial trauma: analysis of 4786 patients. Plast Reconstr Surg 2009;123(4):1293-1301

18 AO Foundation. AO Surgery reference. Available at: https:// www2.aofoundation.org/. Accessed December 20, 2016

19 Shetty V, Freymiller E. Teeth in the line of fracture: a review. J Oral Maxillofac Surg 1989;47(12):1303-1306

20 Baykul T, Erdem E, Dolanmaz D, Alkan A. Impacted tooth in mandibular fracture line: treatment with closed reduction. J Oral Maxillofac Surg 2004;62(3):289-291

21 Tay AB, Lai JB, Lye KW, et al. Inferior alveolar nerve injury in trauma-induced mandible fractures. J Oral Maxillofac Surg 2015; 73(7):1328-1340

22 Wilson IF, Lokeh A, Benjamin CI, et al. Prospective comparison of panoramic tomography (zonography) and helical computed tomography in the diagnosis and operative management of mandibular fractures. Plast Reconstr Surg 2001;107(6):1369-1375

23 Roth FS, Kokoska MS, Awwad EE, et al. The identification of mandible fractures by helical computed tomography and Panorex tomography. J Craniofac Surg 2005;16(3):394-399

24 Ellis E III, Miles BA. Fractures of the mandible: a technical perspective. Plast Reconstr Surg 2007;120(7, Suppl 2):76S-89S
25 Nishioka GJ, Van Sickels JE. Transoral plating of mandibular angle fractures: a technique. Oral Surg Oral Med Oral Pathol 1988; 66(5):531-535

26 Ellis E III. A study of 2 bone plating methods for fractures of the mandibular symphysis/body. J Oral Maxillofac Surg 2011;69(7): 1978-1987

27 Agnihotri A, Prabhu S, Thomas S. A comparative analysis of the efficacy of cortical screws as lag screws and miniplates for internal fixation of mandibular symphyseal region fractures: a randomized prospective study. Int J Oral Maxillofac Surg 2014; 43(1):22-28

28 Gutta R, Tracy K, Johnson C, James LE, Krishnan DG, Marciani RD. Outcomes of mandible fracture treatment at an academic tertiary hospital: a 5-year analysis. J Oral Maxillofac Surg 2014;72(3): 550-558

29 Schubert W, Kobienia BJ, Pollock RA. Cross-sectional area of the mandible. J Oral Maxillofac Surg 1997;55(7):689-692, discussion 693

30 Dodson TB. Third molars may double the risk of an angle fracture of the mandible. Evid Based Dent 2004;5(3):78. Doi: 10.1038/sj. ebd.6400263

31 James RB, Fredrickson C, Kent JN. Prospective study of mandibular fractures. J Oral Surg 1981;39(4):275-281

32 Ellis E III. A prospective study of 3 treatment methods for isolated fractures of the mandibular angle. J Oral Maxillofac Surg 2010; 68(11):2743-2754

33 Chuong R, Donoff RB, Guralnick WC. A retrospective analysis of 327 mandibular fractures. J Oral Maxillofac Surg 1983;41(5): 305-309

34 Ellis E III. Management of fractures through the angle of the mandible. Oral Maxillofac Surg Clin North Am 2009;21(2):163-174

35 Tate GS, Ellis E III, Throckmorton G. Bite forces in patients treated for mandibular angle fractures: implications for fixation recommendations. J Oral Maxillofac Surg 1994;52(7):734-736

36 Champy M, Lodde JP. [Osteosynthesis of the external orbital cavity using screwed plates. Therapeutic indications and results]. Rev Otoneuroophtalmol 1976;48(4):243-248

37 Al-Moraissi EA, Ellis E III. What method for management of unilateral mandibular angle fractures has the lowest rate of postoperative complications? A systematic review and metaanalysis. J Oral Maxillofac Surg 2014;72(11):2197-2211

38 Cillo JE Jr, Ellis E III. Management of bilateral mandibular angle fractures with combined rigid and nonrigid fixation. J Oral Maxillofac Surg 2014;72(1):106-111

39 Booth PW, Schendel SA, Hausamen JE II. Maxillofacial surgery. 1; Philadelphia, PA: Churchill Livingstone Elsevier; 2007

40 Zachariades N, Mezitis M, Mourouzis C, Papadakis D, Spanou A. Fractures of the mandibular condyle: a review of 466 cases. Literature review, reflections on treatment and proposals. J Craniomaxillofac Surg 2006;34(7):421-432

41 Zide MF, Kent JN. Indications for open reduction of mandibular condyle fractures. J Oral Maxillofac Surg 1983;41(2):89-98

42 Ellis E III. Discussion: which factors are associated with open reduction of adult mandibular condylar injuries? Plast Reconstr Surg 2016;137(6):1822-1823

43 Marker P, Nielsen A, Bastian HL. Fractures of the mandibular condyle. Part 1: patterns of distribution of types and causes of fractures in 348 patients. Br J Oral Maxillofac Surg 2000;38(5): 417-421

44 Santler G, Kärcher H, Ruda C, Köle E. Fractures of the condylar process: surgical versus nonsurgical treatment. J Oral Maxillofac Surg 1999;57(4):392-397, discussion 397-398

45 Kyzas PA, Saeed A, Tabbenor O. The treatment of mandibular condyle fractures: a meta-analysis. J Craniomaxillofac Surg 2012; 40(8):e438-e452

46 Haug RH, Assael LA. Outcomes of open versus closed treatment of mandibular subcondylar fractures. J Oral Maxillofac Surg 2001; 59(4):370-375, discussion 375-376 
47 Walker RV. Condylar fractures: nonsurgical management. J Oral Maxillofac Surg 1994;52(11):1185-1188

48 Ellis E III, Simon P, Throckmorton GS. Occlusal results after open or closed treatment of fractures of the mandibular condylar process. J Oral Maxillofac Surg 2000;58(3):260-268

49 Ellis E III, Throckmorton G. Facial symmetry after closed and open treatment of fractures of the mandibular condylar process. J Oral Maxillofac Surg 2000;58(7):719-728, discussion 729-730

50 Schneider M, Erasmus F, Gerlach KL, et al. Open reduction and internal fixation versus closed treatment and mandibulomaxillary fixation of fractures of the mandibular condylar process: a randomized, prospective, multicenter study with special evaluation of fracture level. J Oral Maxillofac Surg 2008;66(12):2537-2544

51 Al-Moraissi EA, Ellis E III. Surgical treatment of adult mandibular condylar fractures provides better outcomes than closed treatment: a systematic review and meta-analysis. J Oral Maxillofac Surg 2015;73(3):482-493

52 Suzuki T, Kawamura H, Kasahara T, Nagasaka H. Resorbable polyL-lactide plates and screws for the treatment of mandibular condylar process fractures: a clinical and radiologic follow-up study. J Oral Maxillofac Surg 2004;62(8):919-924

53 Singh V, Bhagol A, Goel M, Kumar I, Verma A. Outcomes of open versus closed treatment of mandibular subcondylar fractures: a prospective randomized study. J Oral Maxillofac Surg 2010;68(6): 1304-1309

54 Gupta M, Iyer N, Das D, Nagaraj J. Analysis of different treatment protocols for fractures of condylar process of mandible. J Oral Maxillofac Surg 2012;70(1):83-91

55 Marker P, Nielsen A, Bastian HL. Fractures of the mandibular condyle. Part 2: results of treatment of 348 patients. Br J Oral Maxillofac Surg 2000;38(5):422-426

56 Forouzanfar T, Lobbezoo F, Overgaauw M, et al. Long-term results and complications after treatment of bilateral fractures of the mandibular condyle. Br J Oral Maxillofac Surg 2013;51(7):634-638

57 Ellis E III, Kellman RM, Vural E. Subcondylar fractures. Facial Plast Surg Clin North Am 2012;20(3):365-382

58 Ellis E III, Price C. Treatment protocol for fractures of the atrophic mandible. J Oral Maxillofac Surg 2008;66(3):421-435

59 Bradley JC. Age changes in the vascular supply of the mandible. Br Dent J 1972;132(4):142-144

60 Bruce RA, Strachan DS. Fractures of the edentulous mandible: the Chalmer J. Lyons Academy study. J Oral Surg 1976;34(11):973-979

61 Bruce RA, Ellis E III. The second Chalmers J. Lyons Academy study of fractures of the edentulous mandible. J Oral Maxillofac Surg 1993;51(8):904-911

62 Buchbinder D. Treatment of fractures of the edentulous mandible, 1943 to 1993: a review of the literature. J Oral Maxillofac Surg 1993;51(11):1174-1180

63 Luhr HG, Reidick T, Merten HA. Results of treatment of fractures of the atrophic edentulous mandible by compression plating: a retrospective evaluation of 84 consecutive cases. J Oral Maxillofac Surg 1996;54(3):250-254, discussion 254-255

64 Eyrich GK, Grätz KW, Sailer HF. Surgical treatment of fractures of the edentulous mandible. J Oral Maxillofac Surg 1997;55(10): 1081-1087, discussion 1087-1088

65 Iatrou I, Samaras C, Theologie-Lygidakis N. Miniplate osteosynthesis for fractures of the edentulous mandible: a clinical study 1989-96. J Craniomaxillofac Surg 1998;26(6):400-404

66 Kunz C, Hammer B, Prein J. [Fractures of the edentulous atrophic mandible. Fracture management and complications]. . [in German] Mund Kiefer Gesichtschir 2001;5(4):227-232

67 Allard RH, Lekkas C. Unusual healing of a fracture of an atrophic mandible. Report of a case. Oral Surg Oral Med Oral Pathol 1983; 55(6):560-563

68 Zachariades N, Papavassiliou D, Triantafyllou D, et al. Fractures of the facial skeleton in the edentulous patient. J Maxillofac Surg 1984;12(6):262-266
69 Rowe NL. Fractures of the jaws in children. J Oral Surg 1969;27(7): 497-507

70 Kaban LB, Mulliken JB, Murray JE. Facial fractures in children: an analysis of 122 fractures in 109 patients. Plast Reconstr Surg 1977;59(1):15-20

71 Sherick DG, Buchman SR, Patel PP. Pediatric facial fractures: a demographic analysis outside an urban environment. Ann Plast Surg 1997;38(6):578-584, discussion 584-585

72 Smith DM, Bykowski MR, Cray JJ, et al. 215 mandible fractures in 120 children: demographics, treatment, outcomes, and early growth data. Plast Reconstr Surg 2013;131(6):1348-1358

73 Owusu JA, Bellile E, Moyer JS, Sidman JD. Patterns of pediatric mandible fractures in the United States. JAMA Facial Plast Surg 2016;18(1):37-41

74 Kaban LB. Diagnosis and treatment of fractures of the facial bones in children 1943-1993. J Oral Maxillofac Surg 1993; 51(7):722-729

75 Siy RW, Brown RH, Koshy JC, Stal S, Hollier LH Jr. General management considerations in pediatric facial fractures. J Craniofac Surg 2011;22(4):1190-1195

76 James DR. Maxillofacial injuries in children. Rowe NL, Williams JL. Maxillofacial Injuries. New York: Churchill Livingstone; 1985: 538-558

77 Wolfswinkel EM, Weathers WM, Wirthlin JO, Monson LA, Hollier LH Jr, Khechoyan DY. Management of pediatric mandible fractures. Otolaryngol Clin North Am 2013;46(5):791-806

78 MacLennan WD. Consideration of 180 cases of typical fractures of the mandibular condylar process. Br J Plast Surg 1952;5(2):122-128

79 Ferreira PC, Amarante JM, Silva PN, et al. Retrospective study of 1251 maxillofacial fractures in children and adolescents. Plast Reconstr Surg 2005;115(6):1500-1508

80 Demianczuk AN, Verchere C, Phillips JH. The effect on facial growth of pediatric mandibular fractures. J Craniofac Surg 1999;10(4):323-328

81 Schweinfurth JM, Koltai PJ. Pediatric mandibular fractures. Facial Plast Surg 1998;14(1):31-44

82 Lund K. Mandibular growth and remodelling processes after condylar fracture. A longitudinal roentgencephalometric study. Acta Odontol Scand Suppl 1974;32(64):3-117

83 Ghasemzadeh A, Mundinger GS, Swanson EW, Utria AF, Dorafshar AH. Treatment of pediatric condylar fractures: a 20-year experience. Plast Reconstr Surg 2015;136(6):1279-1288

84 Rémi M, Christine MC, Gael P, Soizick P, Joseph-André J. Mandibular fractures in children: long term results. Int J Pediatr Otorhinolaryngol 2003;67(1):25-30

85 Naran S, Keating J, Natali M, et al. The safe and efficacious use of arch bars in patients during primary and mixed dentition: a challenge to conventional teaching. Plast Reconstr Surg 2014; 133(2):364-366

86 Iizuka T, Lindqvist C. Rigid internal fixation of fractures in the angular region of the mandible: an analysis of factors contributing to different complications. Plast Reconstr Surg 1993;91(2): 265-271, discussion 272-273

87 Anderson T, Alpert B. Experience with rigid fixation of mandibular fractures and immediate function. J Oral Maxillofac Surg 1992; 50(6):555-560, discussion 560-561

88 lizuka T, Lindqvist C, Hallikainen D, Paukku P. Infection after rigid internal fixation of mandibular fractures: a clinical and radiologic study. J Oral Maxillofac Surg 1991;49(6):585-593

89 Odom EB, Snyder-Warwick AK. Mandible fracture complications and infection: the influence of demographics and modifiable factors. Plast Reconstr Surg 2016;138(2):282e-289e

90 Haug RH, Schwimmer A. Fibrous union of the mandible: a review of 27 patients. J Oral Maxillofac Surg 1994;52(8):832-839

91 Mathog RH, Toma V, Clayman L, Wolf S. Nonunion of the mandible: an analysis of contributing factors. J Oral Maxillofac Surg 2000;58(7):746-752, discussion 752-753 